\title{
SECTIONAL SPEED CONTROL SYSTEM AS SYSTEM TO EVALUATE DRIVER'S BEHAVIOUR ON RURAL ROADS
}

\author{
Robert Ziolkowski \\ Bialystok University of Technology, Poland \\ robert.ziolkowski@pb.edu.pl
}

\begin{abstract}
Travel speed remains within the most important factors influencing the road safety. It is not only the severity of a crash that speed affects but velocity is also related to the risk of being involved in a crash. In Poland the problem of speeding drivers is widely common and similarly to other European countries speed is indicated as a dominant cause of accident occurrence. As a response to that many activities have been undertaken to better control drivers' behaviour. One of the recently implemented prevention measures on chosen national roads in rural areas is a sectional speed control system. First statistics show that within the area of the sectional speed system the average travel speed has decreased. However, these statistics do not consider the presence of other than passenger vehicles in a traffic flow and their possible influence on the average recorded speed. The aim of this paper is to examine driver's average speed depending on the geometric characteristics and type of a vehicle. Speed surveys were conducted with the use of ANPR (Automatic Plate Number Recognition) cameras. Tested sections included 12 sections of regional and 10 sections of province roads located in Podlaskie voivodship, Poland. During the measurements the traffic flow was composed of trucks, delivery vehicles and passenger cars. These types of vehicles were extracted and average travel speed was calculated for each group. Statistical analysis was performed between separated groups of users in order to evaluate the existence of statistically significant differences and to assess the influence of chosen road parameters and vehicle type on the average speed.
\end{abstract}

Keywords: speed, sectional speed, driver's behaviour, road geometry.

\section{Introduction}

Driver's behaviour is influenced by many factors related to road, vehicle and human characteristics. However, the most important factor is speed, which is pointed as a dominant factor in road safety analyses and road crashes occurrence. On the other hand, from the drivers' point of view travel speed is the most important quality assessment factor and drivers wish to drive in good and safe conditions even though those expectations can be mutually exclusive. Driving conditions on rural roads are closely related to the road environment, which has already been widely investigated by many researchers. However, most of them were mainly based on spot speed and operating speed. Wang et al. [1] studied the effects of cross section characteristics and adjacent land use on operating speeds in Atlanta and as a result they found a positive correlation of the operation speed with the number of driving lanes. The influence of the geometric parameters on the operating speed on multi-lanes highways was also confirmed by other researchers [2-5]. The relationship between spot speed and horizontal curves was investigated by Jacob et al. $[6,7]$ on two-lane highways in hilly terrain. They investigated the relationship between $85^{\text {th }}$ percentile operating speed and basic geometric features of the horizontal curves like the radius, deviation angle and sight distance. As a result, applying regression analysis, a model that allows to predict the operating speed for horizontal curves was elaborated, but it was valid only for passenger cars. More extended field study, but focused on changes of drivers' speed behaviour on rural roads in relation to the operating speed over the time, was conducted by Radalj and Sultana [8]. Their investigations included analysis of the drivers' compliance to speed limit in free-flow driving conditions during 12 annual speed surveys. Changes in driver speed behaviours were used as measures of effectiveness of speed enforcement programs and other road safety initiatives undertaken by road authorities. In many studies to develop the operating speed models radar speed guns were used in speed surveys, but to avoid human errors possible in this method, some researchers used in-vehicle GPS equipment for speed collections [9-11]. This method allows to obtain more accurate data, as well as more precisely determine the minimum or maximum speed on curves to calculate the real operating speed. The need for regional speed analyses was already stated by Lamm and Smith [12], who showed that drivers' speed behaviour depends not only on the country, but also on the smaller areas under investigations.

The main goal of this paper is to analyses drivers' behaviour on rural roads based on sectional speed measurements. Speed investigations were conducted with the use of ANPR (Automatic Number 
Plate Recognition) cameras, which allowed to analyse average speed on road segments of different lengths and geometric characteristics with the consideration given to traffic composition.

\section{Research area and speed surveys}

Research area included 12 regional and 10 district roads selected for comparison analyses. All roads are situated in Podlaskie province, Poland and their selection was based on different geometric characteristics. Speed surveys on those sections were performed with the use of a set of two ANPR (Automatic Number Plate Recognition) cameras installed on the check points. Vehicles passing through the check points located at the beginning and end point of every measured section were detected and recorded by video-cameras. A camera read the vehicle's number plate and encrypted it using the cryptology methods. When the vehicle exited the section, the number plate was again read and matched to the plate captured at the beginning of the section. Using these two data records and the elapsed time between them, the system calculated the average speed based on the length of the section. Behaviour was based on sectional speed changes related to the following parameters:

- width of a driving lane, $\mathrm{m}$,

- road curvature, degrees,

- average speed $V_{\text {avg }}, \mathrm{km} \cdot \mathrm{h}^{-1}$,

- $\quad$ 85th percentile of speed $V \_85, \mathrm{~km} \cdot \mathrm{h}^{-1}$,

- traffic composition.

\section{Research results and discussion}

Speed surveys results and basic characteristics of the speed and geometry of investigated roads are presented in Table 1.

Table 1

Speed characteristics on investigated roads

\begin{tabular}{|c|c|c|c|c|c|c|c|}
\hline $\begin{array}{c}\text { Road } \\
\text { section }\end{array}$ & $\begin{array}{c}\text { Speed limit, } \\
\mathbf{k m} \cdot \mathbf{h}^{-1}\end{array}$ & $\begin{array}{c}\text { Length of } \\
\text { a section, } \mathrm{km}\end{array}$ & $\begin{array}{c}V_{\text {avg g }}, \\
\mathbf{k m} \cdot \mathbf{h}^{-1}\end{array}$ & $\begin{array}{c}P_{e s}, \\
\%\end{array}$ & $\begin{array}{c}V \_\mathbf{8 5}, \\
\mathbf{k m} \cdot \mathbf{h}^{-1}\end{array}$ & $\begin{array}{c}\text { Curvature } \\
{ }^{0} \cdot \mathbf{k m}^{-1}\end{array}$ & $S D$ \\
\hline \multicolumn{8}{|c|}{$\begin{array}{ll}\text { Regional roads } \\
\end{array}$} \\
\hline $\mathrm{R} 1$ & 90 & 9.58 & 80.9 & 78.0 & 94.1 & 2.6 & 13.5 \\
\hline R2 & 90 & 3.62 & 80.2 & 24.7 & 93.4 & 10.6 & 12.8 \\
\hline R3 & 90 & 2.64 & 80.4 & 21.3 & 94.3 & 16.9 & 12.2 \\
\hline $\mathrm{R} 4$ & 90 & 3.01 & 75.9 & 6.7 & 84.9 & 23.4 & 8.9 \\
\hline R5 & 90 & 3.22 & 74.4 & 5.5 & 88.0 & 33.1 & 9.6 \\
\hline R6 & 90 & 3.64 & 75.9 & 21.4 & 84.1 & 36.4 & 11.5 \\
\hline R7 & 90 & 3.22 & 73.1 & 6.7 & 84.6 & 42.9 & 12.2 \\
\hline R8 & 90 & 3.84 & 72.5 & 9.9 & 84.6 & 45.4 & 10.5 \\
\hline R9 & 90 & 3.22 & 71.6 & 5.9 & 84.1 & 56.5 & 9.4 \\
\hline R10 & 90 & 7.75 & 72.9 & 4.5 & 86.7 & 61.7 & 10.9 \\
\hline R11* & 50 & 1.35 & 65.0 & 94.4 & 74.2 & 35.2 & 8.6 \\
\hline R12* & 50 & 1.12 & 59.4 & 78 & 71.3 & 51.9 & 7.9 \\
\hline \multicolumn{8}{|c|}{ District roads } \\
\hline D1 & 90 & 2.97 & 77.6 & 7 & 86.8 & 6.7 & 9.1 \\
\hline D2 & 90 & 8.38 & 90.5 & 57 & 102.2 & 8.0 & 13.5 \\
\hline D3 & 90 & 3.67 & 77.5 & 22 & 91.5 & 17.5 & 12.7 \\
\hline D4 & 90 & 8.07 & 79.8 & 18 & 88.7 & 33.5 & 8.9 \\
\hline D5 & 90 & 3.74 & 74.8 & 10 & 85.5 & 34.1 & 10.5 \\
\hline D6 & 90 & 4.71 & 70.6 & 4 & 79.0 & 41.8 & 12.2 \\
\hline D7 & 90 & 4.37 & 81.8 & 11 & 91.0 & 48.6 & 11.6 \\
\hline D8 & 90 & 3.32 & 66.9 & 0 & 76.0 & 58.0 & 8.7 \\
\hline D9 & 90 & 3.66 & 76.0 & 9 & 87.8 & 71.5 & 11.9 \\
\hline D10* & 50 & 1.01 & 66.1 & 6 & 78.5 & 55.3 & 13.6 \\
\hline
\end{tabular}

* - through roads

$P_{e s}-$ participation of drivers with excessive speed 
The data presented in Table 1 show the results of the sectional speed recorded on regional and district roads. Average speed on regional roads remains below the posted speed limit in case of rural roads. Average speed on the road segment passing through urban area with the speed limit $50 \mathrm{~km} \cdot \mathrm{h}^{-1}$ on both sections exceeded the existing speed limit. In case of district roads, except one road section $\mathrm{D} 2$, where average speed was slightly over the speed limit $\left(V_{\text {avg }}=90.5 \mathrm{~km} \cdot \mathrm{h}^{-1}\right)$, the average speed values remain distinctly below the speed limit and the range of speed varied from $66.9 \mathrm{~km} \cdot \mathrm{h}^{-1}$ to $81.8 \mathrm{~km} \cdot \mathrm{h}^{-1}$. Average speed on a section D10 passing through a built-up area is over the speed limit, similarly to the sections of regional roads with the speed limit $50 \mathrm{~km} \cdot \mathrm{h}^{-1}$. Considering $85^{\text {th }}$ percentile of speed the existing speed limit of $90 \mathrm{~km} \cdot \mathrm{h}^{-1}$ was exceeded on 3 out of 10 sections in case of rural roads and on 3 out of 9 sections of district roads.

Standard deviation of speed remains on similar levels in regional and district roads and opposite to expectations is not related to the average speed value. The highest values of standard deviation $(\mathrm{SD}=13.5)$ were recorded on roads $\mathrm{R} 1, \mathrm{D} 1$ and $\mathrm{D} 10^{*}$, where the average speed values were respectively $V_{\text {avg }}=80.9 \mathrm{~km} \cdot \mathrm{h}^{-1}, V_{\text {avg }}=90.5 \mathrm{~km} \cdot \mathrm{h}^{-1}$ and $V_{\text {avg }}=66.1 \mathrm{~km} \cdot \mathrm{h}^{-1}$.

Another road geometry-related parameter influencing the driver's behavior is the width of a driving lane and a shoulder. Percentage of speeding drivers in relation to these parameters is presented in Figure $1 \mathrm{a}$ and $1 \mathrm{~b}$, respectively. Figure $1 \mathrm{c}$ and $1 \mathrm{~d}$ presents plots of the average speed values with $95 \%$ confidence level.

a)

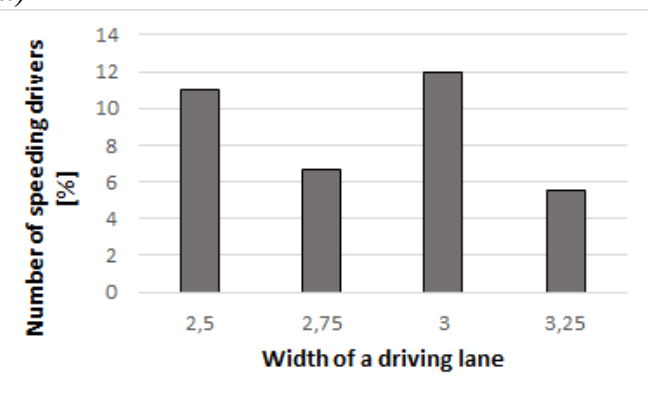

c)

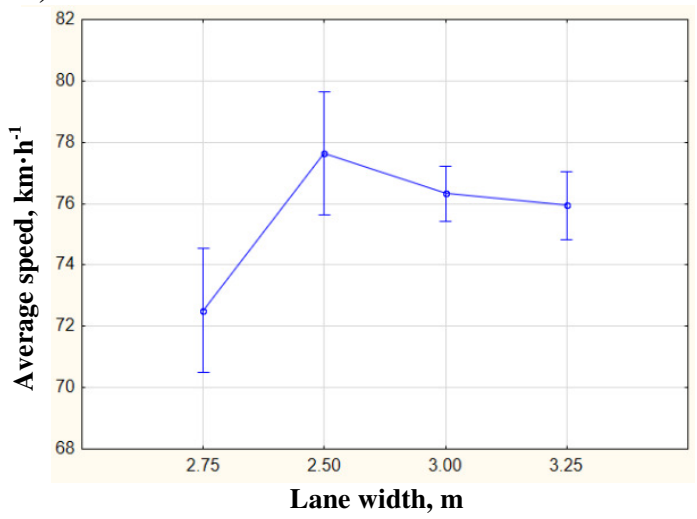

b)

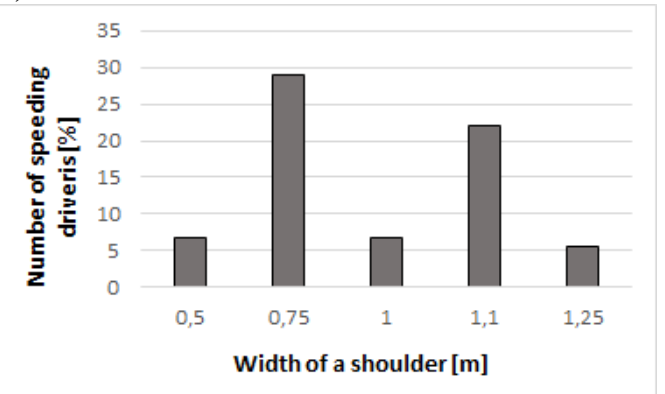

d)

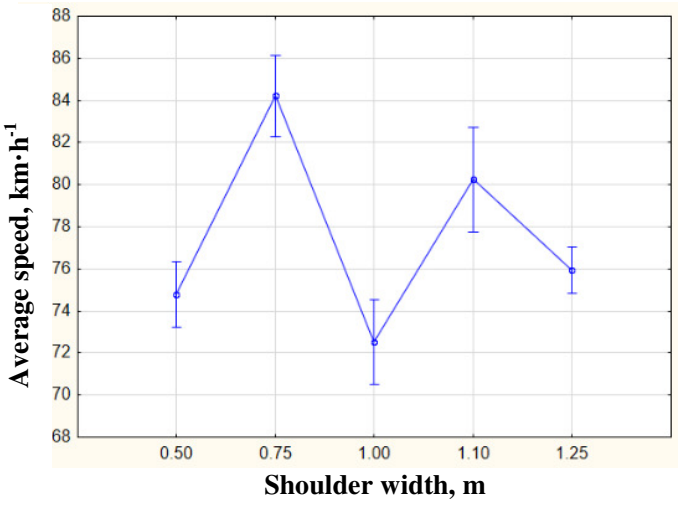

Fig. 1. Average speed values and number of speeding drivers in relation to width of driving lane and shoulder for regional roads

On the tested roads the width of the driving lane varied from $2.50 \mathrm{~m}$ to $3.25 \mathrm{~m}$. Results of speed survey show that influence of a lane and a shoulder width on the percent of speeding drivers is ambiguous and the width of a driving lane or shoulder is not correlated with the numbers of drivers travelling with excessive speed, nor with average speed. The number of speeding drivers varied between $5.5 \%$ (lane width $3.25 \mathrm{~m}$ ) and $12.0 \%$ (lane width $3.0 \mathrm{~m}$ ) in case of the lane width. In case of the shoulder width the values were higher and varied between $5.5 \%$ (shoulder width $1.25 \mathrm{~m}$ ) and $29.0 \%$ (shoulder width $0.75 \mathrm{~m}$ ). A very high number of speeding drivers was recorded on segments of regional roads located in built-up areas ( $78 \%$ and $94.4 \%$ ), but in case of D10 section the number of speeding drivers was surprisingly small $(6 \%)$. It can be concluded that the speed limit is generally not accepted by drivers and too many of them drove over the speed limit $(78.1 \%$ on roads with driving 
lane equal $3.25 \mathrm{~m}$ and $86.2 \%$ on roads with driving lane equal $3.00 \mathrm{~m}$ ). Similar phenomena have been already earlier observed on national roads in Poland, but in a smaller scale [13]. Due to relatively short lengths and the limited number of sections located in built-up areas it was not possible to evaluate valuably the influence of a road curvature on the drivers' behaviour. In built-up areas each of the analysed sections had only one horizontal arc, which made it impossible for adequate analyses. Such relationship could be evaluated on other roads located outside of built-up areas, where analysed sections had at least three curvatures. Figure 2 presents the relationship between the average speed and the road curvature for regional roads. Statistical analyses confirmed high negative correlation between the average speed and the road curvature $(r=-0.9312)$ and the statistical significance of the correlation $(p=0.00009)$. In case of district roads, the correlation is also negative, but the correlation coefficient is essentially smaller $(r=-0.05513)$ and is not statistically significant $(p=0.1239)$. The highest average speeds were recorded on roads with the lowest curvature $\left(V_{\text {avg }}=80.9 \mathrm{~km} \cdot \mathrm{h}^{-1}\right.$ and $V_{\text {avg }}=78.5 \mathrm{~km} \cdot \mathrm{h}^{-1}$ for regional and district roads, respectively). Considering the correlation between the $85^{\text {th }}$ percentile of speed and the road curvature the significant dependency $(r=-0.7803$; $p=0.00774$ ) was confirmed for regional roads (Figure 3a), whereas for district roads (Figure 3b) the dependency was statistically insignificant $(p=0.1403)$. Conducted variance analyses confirmed significant influence of both the driving lane and shoulder width on the average speed with $p=0.0044$ and $p=0.0000$, respectively.

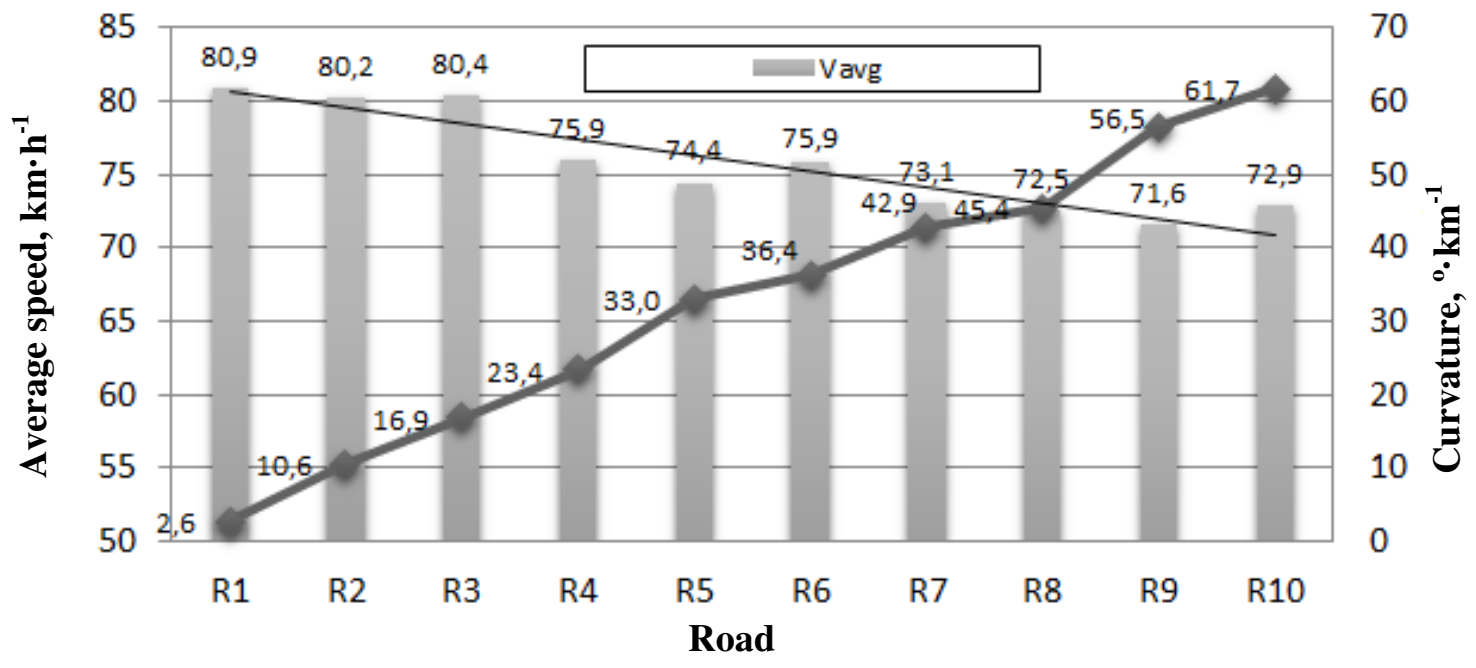

Fig. 2. Relationship between average speed and road curvature on regional roads

a)

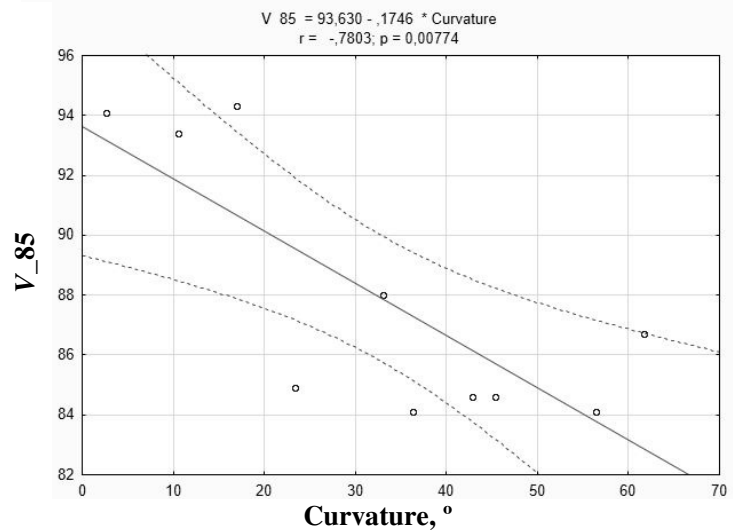

b)

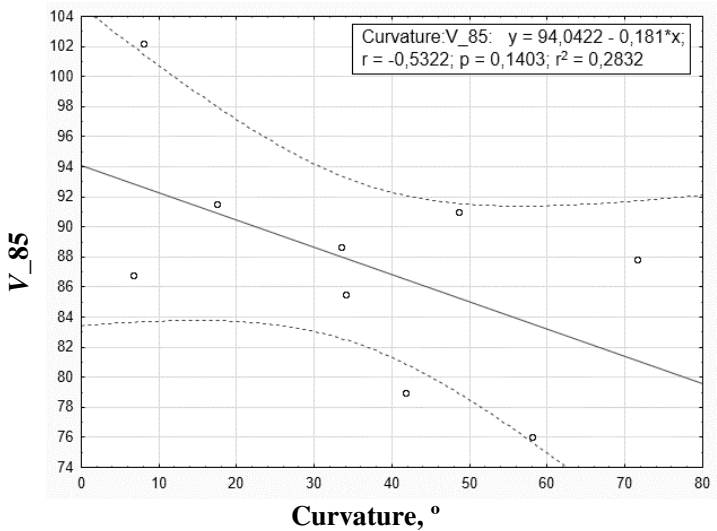

Fig. 3. Scatterplots of correlations between $85^{\text {th }}$ percentile of speed and road curvature with $95 \%$ confidence interval a) regional roads and b) district roads

Additional analyses were conducted in order to evaluate drivers' behaviour in relation to the traffic composition. Recorded vehicles were categorized into passenger cars (P), delivery vehicles (D) and trucks $(\mathrm{T})$. Variance analysis has proved the existence of statistically significant differences (Figure 4a) between the average speeds within the analysed groups of vehicles on district roads 
$(p=0.018328)$ and lack of such a significant difference (Figure 4b) in case of regional roads $(p=0.155905)$. These statements are valid as long as we consider categorized vehicles recorded on all district or regional roads. However, while regional roads were investigated separately, statistical significance between the average speeds was stated on some segments (R1, R2, R4, R7). Detailed analysis has revealed that crucial effect on the significance of difference between the average speeds has lower average speed recorded for trucks in comparison to the average speed of passenger cars $(p=0.00849)$. Mutual comparisons conducted for the other pairs of vehicles presented in Figure 4c and Figure $4 \mathrm{~d}$ showed no significant differences $(p=0.06364$ for P-D comparison and $p=0.1311$ for T-D comparison).

a)

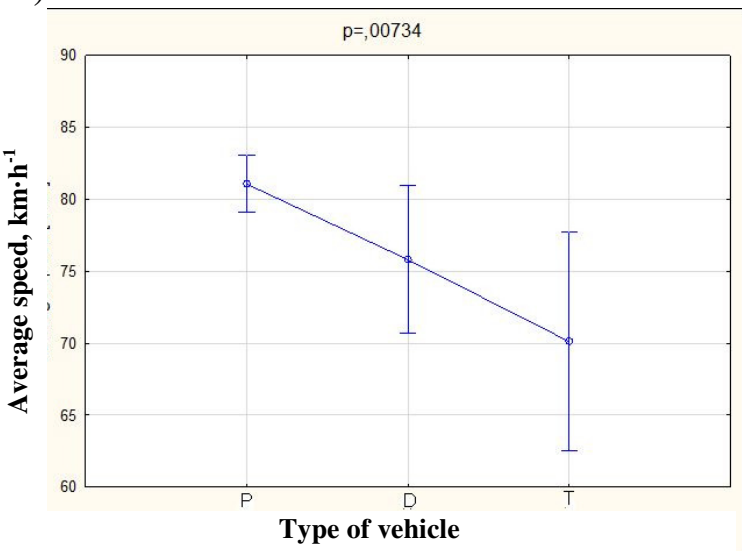

c)

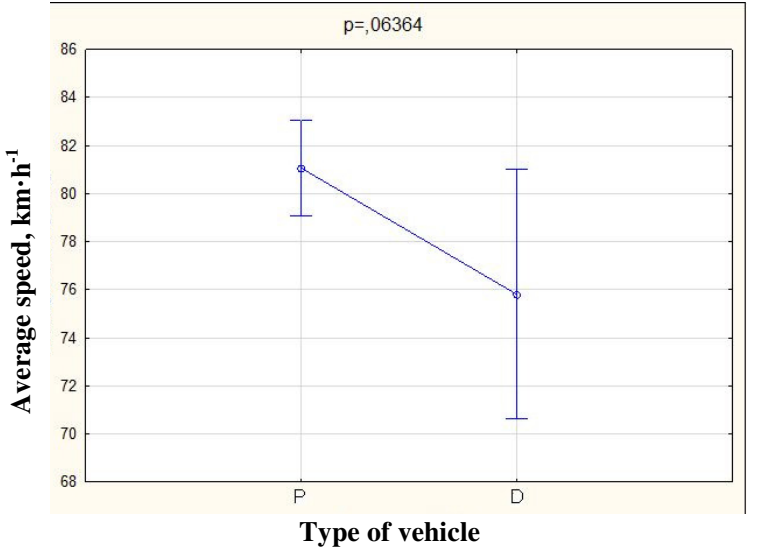

b)

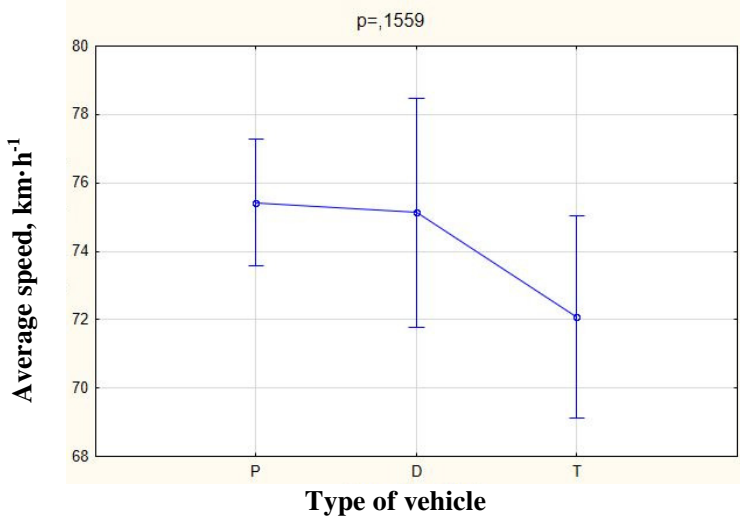

d)

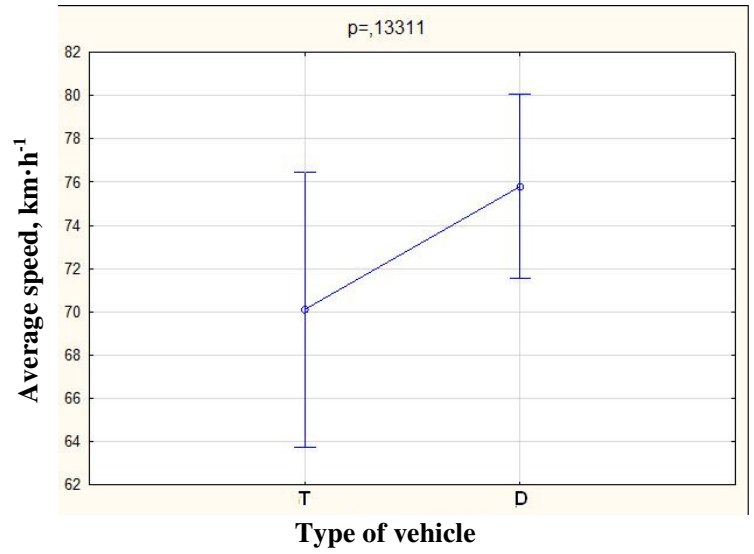

Fig. 4. Box-whisker plots reflecting average speed and type of vehicle for a) district roads and b) regional roads

\section{Conclusions}

The conducted speed surveys and analyses are based on average sectional speed results and revealed lack of speed uniformity in relation to road characteristics. Speed surveys conducted on regional and district roads located in Podlaskie voivodship have revealed that drivers' behaviour in terms of the average travel speed depends on the road curvature and the highest speeds were recorded on roads with lowest curvatures. The relationship between the average speed and the width of the driving lane and shoulder is ambiguous and there is no simple correlation bounding these variables. Speed surveys and analyses are crucial for any activities undertaken towards safety improvements on roads. The research results show that such activities should be each time preceded by detailed research rather than based on the generalised conclusions drawn on the basis of few test segments. Considering traffic conditions an important issue is speed homogeneity. The conducted analyses proved that the average travel speed depends on the type of a vehicle in case of district roads, where the percentage of vehicles others than passenger cars varied between $14 \%$ and $24 \%$. On regional roads the percentage of passenger cars varied from $82 \%$ to $91 \%$ and the influence of the type a vehicle does not 
significantly influence on the average speed, but deepened analyses of individual sections showed that in some cases such a difference exists.

\section{Acknowledgements}

The research was supported by the Project No S/WBiIS/1/15 and it was financially supported by the Ministry of Science and Higher Education, Poland.

\section{References}

[1] Wang J., Dixon K, Li H., Hunter M.P. Operating speed model for low-speed urban tangent sections based on in-vehicle global positioning systems, Transport RES REC, 1961 (2006), pp. 24-33.

[2] Himes S.C., Donnell E.T. Speed prediction models for multi-lane highways: a simultaneous equations approach, Transport ENG - J ASCE, 136 (2), 2010, pp. 124-132;

[3] Figueroa A.M., Tarko A.P. Speed factors on two-lane rural highways in free-flow conditions Transport RES REC, 1912, 2005, pp. 46-49.

[4] Singh D., Zaman M., White L. Modeling of 85th percentile speed for rural highways for enhanced traffic safety. Report submitted to Oklahoma Department of Transportation. FHWA 2211; 2011.

[5] Semeida A.M. Impact of highway geometry and posted speed on operating speed at multi-lane highways in Egypt, Journal of Advanced Research, Vol. 4, Issue 6, 2013, pp. 515-523.

[6] Shallama R.D.K., Ahmed A.M. Operating Speed Models on Horizontal Curves for Two-lane Highways, Transportation Research Procedia, Volume 17, 2016, pp. 445-451.

[7] A. Jacob, R. Dhanya, M.V.L.R. Anjaneyulu. Geometric Design Consistency of Multiple Horizontal Curves on Two-lane Rural Highways, Procedia - Social and Behavioral Sciences, Volume 104, 2013, pp. 1068-1077.

[8] Radalj T., Sultana S. Trends in driver speed behaviours on rural roads network 2000 to 2013, Main Roads Western Australia, Office of Road Safety, 2014.

[9] Perez-Zuriaga, A.M., Garcı 'a Garcı'a, A., Camacho-Torregrosa, F.J., D' Attoma, P., 2010. Modelling operating speed and deceleration on two-lane rural roads with global positioning system data. Transportation Research Record (2171), pp. 11-20.

[10] Cafiso S., Cerni G. New approach to define continuous speed profile models for two lane rural roads. Transportation Research Record (2309), 2012, pp. 157-167.

[11] Memon R.A., Khaskheli G.B., Dahani M.A. Estimation of operating speed on two lane two way roads along N-65 (SIBIeQuetta). International Journal of Civil Engineering 10 (1), 2012, pp. $25-31$

[12] Lamm R., Smith B.L. Curvilinear alignment: an important issue for more consistent and safer road characteristics. Transportation Research Record (1445), 1994, pp. 12-21.

[13]Ziolkowski R. Investigations of section speed on rural roads in Podlaskie voivodeship, World Multidisciplinary Civil Engineering-Architecture-Urban Planning Symposium: WMCAUS 2017, June 12-16, 2017, Prague. 